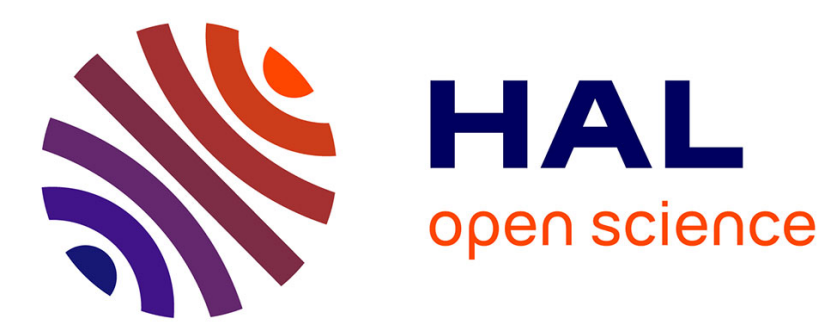

\title{
The behavior of ceramic-matrix composites under thermo-mechanical cyclic conditions
}

\author{
Alain Burr, François Hild, Frederick A Leckie
}

\section{To cite this version:}

Alain Burr, François Hild, Frederick A Leckie. The behavior of ceramic-matrix composites under thermo-mechanical cyclic conditions. Composites Science and Technology, 1998, 58 (5), pp.779-783. 10.1016/S0266-3538(97)00169-3 . hal-02342761

\section{HAL Id: hal-02342761 \\ https://hal.science/hal-02342761}

Submitted on 4 Nov 2019

HAL is a multi-disciplinary open access archive for the deposit and dissemination of scientific research documents, whether they are published or not. The documents may come from teaching and research institutions in France or abroad, or from public or private research centers.
L'archive ouverte pluridisciplinaire HAL, est destinée au dépôt et à la diffusion de documents scientifiques de niveau recherche, publiés ou non, émanant des établissements d'enseignement et de recherche français ou étrangers, des laboratoires publics ou privés. 


\title{
THE BEHAVIOR OF CERAMIC-MATRIX COMPOSITES UNDER THERMO-MECHANICAL CYCLIC CONDITIONS
}

\author{
Alain Burr, ${ }^{a}$ François Hild, ${ }^{a *}$ \& Frederick A. Leckie ${ }^{b}$ \\ "Laboratoire de Mécanique el Technologie, ENS de Cachan/CNRS/Université Paris VI, Cachan, France. \\ ${ }^{b}$ Department of Mechanical and Environmental Engineering, College of Engineering, University of California, Santa Barbara, USA
}

\begin{abstract}
The thermo-mechanical behavior of ceramic-matrix composites is analyzed in the framework of continutum damage mechanics through the introduction of internal variables. The choice of these variables is based upon the study of a micromechanical model describing the degradation mechanisms that have been observed in the material. The model identification is performed by studying two tension tests. The model is then used to predict the result of a Iosipescu shear test. An extension for cyclic and thermal loadings is presented. (C) 1998 Elsevier Science Lid. All rights reserved
\end{abstract}

Keywords: A. ceramic-matrix composite, B. fatigue, internal variables, thermo-mechanical behavior, finiteelement computations

\section{STATE POTENTIAL OF A $[0,90]$ COMPOSITE}

This part deals with the derivation of a constitutive law for a $[0,90]$ (laminated or woven) composite subjected to multiaxial loads in plane stress conditions. The method is based upon the construction of the properties of the composite from the properties of the constituents and the stacking sequence of the layers.

\subsection{Elastic energy density of the composite associated} with matrix cracking and fiber breakage

\subsubsection{Constituent level: matrix and fiber}

The initial behavior of the matrix is assumed to be isotropic: elastic anisotropy is induced by the presence of matrix cracks. The matrix cracks are assumed to be

*To whom correspondence should be addressed at: Laboratoire de Mécanique et Technologie, ENS de Cachan/CNRS/ Université Paris VI, 61 avenue du Président Wilson, F-94235 Cachan Cedex, France. Fax: (+33) 1474022 40; e-mail: hild@Imt.ens-cachan.fr driven by the maximum principal strain directions, $x, y$, developed by the initial applied load. Only two damage variables are needed (these are denoted by $D_{m x}$ and $D_{m y}$ ).

The study of a perpendicular and non-interacting cracked system shows that only the compliances in the two directions $x$ and $y$, and the shear modulus are affected. ${ }^{1}$ The expression for the elastic energy density is given by

$$
\begin{aligned}
\psi_{m}= & \frac{1}{2} \frac{E_{m}}{1-v_{m}^{2}\left(1-D_{m x}\right)\left(1-D_{m y}\right)}\left[\left(1-D_{m x}\right) \epsilon_{m x x}^{2}\right. \\
& +2 v_{m}\left(1-D_{m x}\right)\left(1-D_{m y}\right) \epsilon_{m x x} \epsilon_{m y y} \\
& \left.+\left(1-D_{m y}\right) \epsilon_{m y y}^{2}+4 \tilde{G}_{m}\left(D_{m x}, D_{m y}\right) \epsilon_{m x y}^{2}\right]
\end{aligned}
$$

with

$$
\tilde{G}_{m}\left(D_{m x}, D_{m y}\right)=\frac{G_{m}}{1+\left(\frac{D_{m x}}{1-D_{m x}}+\frac{D_{m y}}{1-D_{m v}}\right) \frac{1}{2\left(1+\nu_{m}\right)}}
$$

where $E_{m}, v_{m}, G_{m}$ are the initial elastic properties of the matrix, $\tilde{G}_{m}$ is the shear modulus of the cracked matrix (dependent upon $D_{m x}$ and $D_{m y}$ ). The components of the strain tensor of the matrix $\underline{\epsilon}_{m}$ expressed in the $x-y$ frame are denoted by $\epsilon_{m x x}, \epsilon_{m y y}$ and $\epsilon_{m x y}$.

The fibers are aligned along the $I$ direction and the fiber breaks are assumed to be perpendicular to the fiber direction. Therefore the elastic energy density of the fibers is given by

$$
\begin{aligned}
\psi_{f}= & \frac{1}{2} \frac{E_{f}}{1-v_{f}^{2}\left(1-D_{f}\right)}\left[\left(1-D_{f}\right) \epsilon_{f 11}^{2}\right. \\
& +2 v_{f}\left(1-D_{f}\right) \epsilon_{f 11} \epsilon_{f 22}+\epsilon_{f 22}^{2} \\
& \left.+4 \tilde{G}_{f}\left(D_{f}\right) \epsilon_{f 12}^{2}\right]
\end{aligned}
$$


with

$$
\tilde{G}_{f}\left(D_{f}\right)=\frac{G_{f}}{1+\frac{D_{1}}{1-D_{f} \frac{1}{2\left(1+v_{l}\right)}}}
$$

where $E_{f}$ is the initial Young's modulus of the fiber, $\bar{G}_{f}(D f)$ the shear modulus of the broken fiber embedded in the matrix, $\epsilon_{f 11}, \epsilon_{122}$ and $\epsilon_{f 12}$ the components of the strain tensor of the fiber $\epsilon_{\text {, }}$ expressed in the $1-2$ frame.

\section{$1.2[0,90]$ composite architecture}

\subsection{Layer level}

A layer consists of fibers aligned along the $/$ direction embedded in a matrix. To determine the behavior of this layer, micro-interface compatibility conditions are written in terms of strains $\underline{\epsilon}^{l}$ and stresses $\underline{\underline{g}}^{l}$ on the layer level. It is more convenient to write the conditions in the 1-2 frame. The following equations are derived by using Voigt's approximation in the fiber direction and Reuss's approximation for the transverse properties

$$
\begin{gathered}
\epsilon_{m 11}=\epsilon_{l 11}=\epsilon_{11}^{l} \\
f_{m 1} \sigma_{m 11}+f_{f} \sigma_{f 11}=\sigma_{11}^{l} \\
f_{m \epsilon_{m 22}}+f_{f} \epsilon_{l 22}=\epsilon_{22}^{l} \\
\sigma_{m 22}=\sigma_{122}=\sigma_{22}^{l} \\
f_{m 1} \epsilon_{m 12}+f_{l} \epsilon_{f 12}=\epsilon_{12}^{l} \\
\sigma_{m 12}=\sigma_{f 12}=\sigma_{12}^{l}
\end{gathered}
$$

where $f_{j}, f_{m}$, denote the volume fractions of the fiber and the matrix, respectively, $\sigma_{i j}^{l}$ and $\epsilon_{i j}^{l}$ are the components of the stress and strain tensors $\underline{\underline{\sigma}}^{l}$ and $\underline{\underline{\epsilon}}^{l}$ in the 12 frame. The solution of the previous system yields

$$
{\underline{\underline{\sigma^{\prime}}}}^{l}=\underline{\underline{\underline{E}}}^{\prime}\left(D_{m x}, D_{m,}, D_{f}\right): \underline{\underline{\epsilon}}^{\prime}
$$

where $\underline{\underline{E}}^{L}\left(D_{\mathrm{mx}}, D_{\mathrm{my}}, D_{f}\right)$ is the stiffness tensor of a layer which is dependent upon all damage variables defined at the constituent level. From eqn (11), the elastic energy density associated to matrix cracking and fiber breakage at the layer level is expressed as

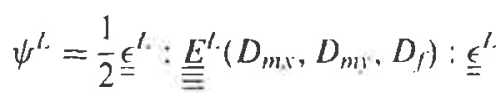

\subsubsection{Composite level}

The elastic behavior of a $[0,90]$ composite system is determined by applying classical laminate theory

$$
\begin{gathered}
\underline{\epsilon}=\underline{\epsilon}^{00}=\underline{\epsilon}^{901} \\
\underline{\underline{\sigma}=} f^{(10)} \underline{\sigma}^{(0)}+f^{90(} \underline{\sigma}^{90}
\end{gathered}
$$

where $f^{010}$ and $f^{* 10}$ denote the volume fraction of the 0 and $90^{\circ}$ layers, respectively, $\underline{\underline{e}}^{(1)}, \underline{\sigma^{(1)}}$ and $\underline{\underline{\epsilon}}^{911}, \underline{\underline{\sigma^{90}}}$ the strain and stress tensors in the $0^{\circ}$ and $90^{\circ}$ layers. By solving eqns (13) and (14), the overall behavior of the composite is defined as

$$
\underline{\underline{\sigma}}=\underline{\underline{\underline{\underline{E}}}}\left(D_{m,}^{00}, D_{m,}^{00}, D_{f}^{(0)}, D_{m x}^{90}, D_{m,}^{90}, D_{f}^{90}\right): \underline{\underline{\epsilon}}
$$

with

$$
\begin{aligned}
& \underline{\underline{\underline{E}}}^{(}\left(D_{m x}^{(0)}, D_{m !}^{00)}, D_{f}^{(0)}, D_{m x}^{(00}, D_{m !}^{90}, D_{f}^{90}\right) \\
& =f^{90} \underline{\underline{\underline{E}}}^{L}\left(D_{m \cdot x}^{00}, D_{m !}^{00}, D_{f}^{(00)}\right) \\
& +f^{40} \underline{\underline{\underline{E}}}^{L}\left(D_{m ! \cdot}^{90}, D_{m !}^{90}, D_{f}^{90}\right)
\end{aligned}
$$

where $\underline{\underline{E}}^{C^{(}}\left(D_{m . x}^{(0)}, D_{m !}^{00}, D_{f}^{001}, D_{m . x}^{(00} D_{m !}^{90}, D_{f}^{9(0)}\right)$ is the fourth order elastic tensor of the composite, which is a function of all damage variables on the constituent level for all layers. From equs (15) and (16), the elastic energy density associated with matrix cracking and fiber breakage can be written on the composite level

$$
\psi^{D}=f^{(0)} \psi^{00}+f^{90} \psi^{90}
$$

where $\psi^{(10)}$ and $\psi^{9(1)}$ are the elastic energy densities of the $0^{\circ}$ and $90^{\circ}$ layers.

\subsection{Energy density associated with debonding and fiber pull-out}

Inelastic strains are essentially due to the interface sliding between the fiber and the matrix. From a micromechanical point of view, sliding can take place as soon as a crack is bridged by fibers. The analysis of these sliding systems leads to the following expression of the stored energy density'

$$
\psi^{s}=\frac{1}{2} E^{s}\left(\frac{\alpha_{11}^{2}}{d_{11}}+\frac{\alpha_{22}^{2}}{d_{22}}\right)+\frac{1}{2} G^{s} \frac{\alpha_{12}^{2}}{d_{12}}
$$

with

$$
\begin{gathered}
E^{S}=\frac{4}{3} \frac{f^{00} E^{00} f^{90} E^{90}}{f^{00} E^{(0)}+f^{90} E^{90}} \\
G^{S}=f^{00} f^{90} G
\end{gathered}
$$

where $E^{(10)}$ and $E^{90}$ are the Young's moduli of the $0^{\circ}$ and $90^{\circ}$ layers in the 1 and 2 directions, $G$ is the shear modulus of a layer expressed in the $I-2$ frame, $d_{11}, d_{22}$ and $d_{12}$ are the damage variables related to interphase debonding, $\alpha_{11}, \alpha_{22}$ and $\alpha_{12}$ are the components of the inelastic strain tensor.

\section{CONSTITUTIVE EQUATIONS}

\subsection{State laws}

The following expression of the free energy density for $[0,90]$ CMCs has been obtained

$$
\begin{aligned}
\psi= & \frac{1}{2}(\underline{\underline{\epsilon}}-\underline{\underline{\alpha}}): \underline{\underline{\underline{\underline{E}}}}^{L}\left(D_{m x}^{00}, D_{m y}^{00}, D_{f}^{00}, D_{m \cdot x}^{90}, D_{m y}^{90}, D_{\digamma}^{90}\right): \\
& (\underline{\underline{\epsilon}}-\underline{\underline{\alpha}})+\psi^{s}
\end{aligned}
$$


From this expression, the associated forces to each internal variable are given by partial differentiation

$$
\begin{aligned}
& \underline{\underline{\epsilon}}=\frac{\partial \psi}{\partial \underline{\underline{\epsilon}}}, Y_{m}=-\frac{\partial \psi}{\partial D_{m}}, Y_{f}=-\frac{\partial \psi}{\partial D_{f}}, \\
& \underline{\underline{X}}=-\frac{\partial \psi}{\partial \underline{\underline{\alpha}}}, y_{i j}=-\frac{\partial \psi}{\partial d_{i j}}
\end{aligned}
$$

where

$$
\begin{aligned}
& D_{m}=\left\{D_{m x}^{00}, D_{m y}^{00}, D_{m x}^{90}, D_{m y}^{90}\right\}, \\
& Y_{m}=\left\{Y_{m x}^{00}, Y_{m y}^{00}, Y_{m x}^{90}, Y_{m y}^{90}\right\}, \\
& D_{f}=\left\{D_{f}^{90}, D_{f}^{90}\right\}, Y_{f}=\left\{Y_{f}^{90}, Y_{f}^{90}\right\} .
\end{aligned}
$$

The evolution laws associated with each mechanism will be identified from simple tests. The identification procedure will be presented in the next sections for a $[0,90]$ layered $\mathrm{SiC} / \mathrm{SiC}$ composite. ${ }^{2}$ The experimental data base consists of two tension tests at $0^{\circ}$ and $45^{\circ}$ (Fig. 1). The strain measurements are performed on $120 \times 10 \times$ $2 \mathrm{~mm}$ coupons, with $(0,90)$ strain gauges. In addition, a stress/strain curve for a Iosipescu shear test $t^{3}$ is given in Fig. 2. The latter will be used to check the model.

\subsection{Evolution laws}

Before the identification of the evolution laws of the model is carried out, the laws needed to define the stress/strain relationship $\underline{\underline{\sigma}}=\underline{\underline{\sigma}}(\underline{\underline{\epsilon}})$ are discussed. $A$ priori, it is necessary to know the 12 evolution laws associated with the 12 internal variables. But, only the six following evolution laws are necessary:

- one law related to matrix cracking $D_{m}=D_{m}\left(Y_{m}\right)$, because the variables $D_{m x}^{00}, D_{m y}^{00}, D_{m x}^{90}$ and $D_{m y}^{90}$ correspond to only one single mechanism, and therefore have the same evolution law;

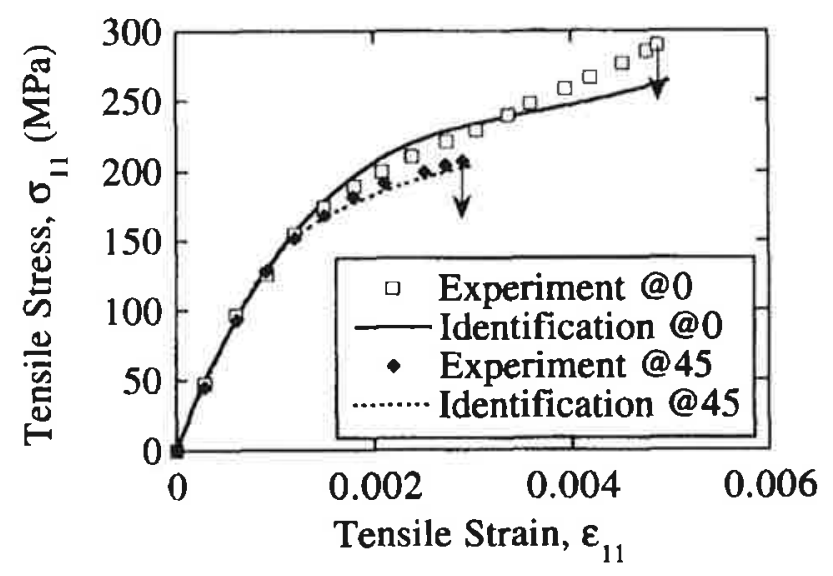

Fig. 1. Tension tests on a $[0,90] \mathrm{SiC} / \mathrm{SiC}$ composite at $0^{\circ}$ and $45^{\circ}$.

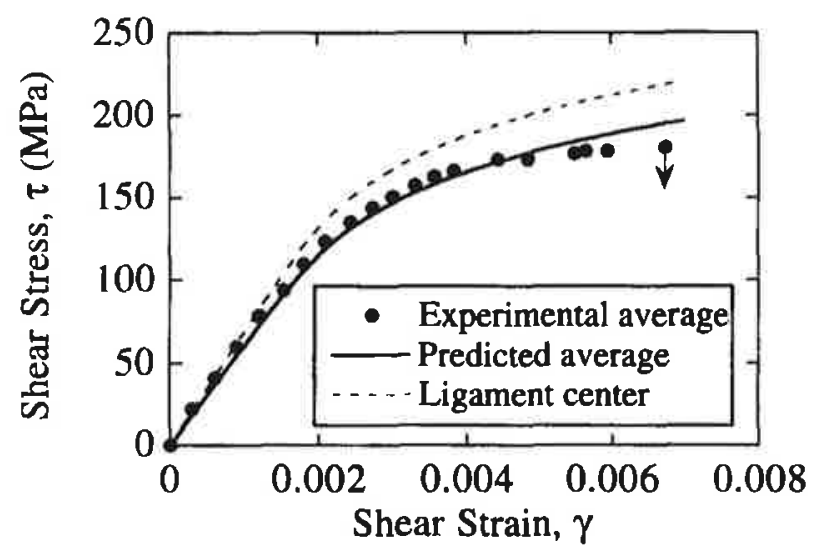

Fig. 2. Iosipescu shear test on a $[0,90] \mathrm{SiC} / \mathrm{SiC}$ composite at $0^{\circ}$.

- one law related to fiber breakage $D_{f}=D_{f}\left(Y_{f}\right), D_{f}^{00}$ and $D_{f}^{90}$ have the same evolution law, because fiber breaks are perpendicular to the fiber direction;

- two laws related to the inelastic strains $\underline{\alpha}=\underline{\alpha}(\underline{X})$, the debonding and sliding mechanisms in the $0^{\circ}$ and $90^{\circ}$ layers are identical, thus $\alpha_{11}$ and $\alpha_{22}$ have the same evolution law. The second one concerns $\alpha_{12}$

- two laws related to in-plane debonding, $d_{\mathrm{ij}}=$ $d_{\mathrm{ij}}\left(y_{\mathrm{ij}}\right), d_{11}$ and $d_{22}$ are assumed to have the same evolution law.

In a one-dimensional analysis ${ }^{4}$ it has been observed that the back stress, $X$, is only a function of the applied stress, $\sigma$. If the relationship is extended to a multiaxial state, then the inelastic strain tensor $\underline{\underline{\alpha}}$ is a function of the stress tensor $\underline{\sigma}$.

For monotonic loads, it is not necessary to have the change in the variables $d_{\mathrm{ij}}$ to derive the behavior of the composite. Neither the state laws nor the evolutions laws are explicit functions of the damage variables, $d_{i j}$. The mechanical effect of these variables is necessary to fully describe the behavior under load-unload sequences which are not presented in this paper.

\subsection{Model identification}

The identification procedure is applied to a layered $[0,90] \mathrm{SiC} / \mathrm{SiC}$ composite, by using the experimental results of Pluvinage. ${ }^{2}$ Only two tension tests are necessary to identify all the evolution laws.

\subsubsection{Elastic properties}

The elastic properties of the Nicalon fibers are given by the manufacturer. Those of the matrix are strongly degraded by processing (porosity, macro-cavities). The mechanical properties of the porous and cracked matrix are determined from the experiments

$$
\begin{aligned}
& E_{f}=200 \mathrm{GPa}, v_{f}=0.25 \\
& E_{m}=156 \mathrm{GPa}, v_{m}=0.2
\end{aligned}
$$




\subsubsection{Kinetic law's}

The evolution law of the damage variable $D_{m}$ modeling matrix cracking is obtained from a tension test at $45^{\circ}$ on the $[0,90]_{\text {s }}$ composite. The evolution law for an elastic brittle material is described by a Weibull law.

$$
D_{m}=D_{\text {sar }}\left(1-\exp \left[-\left(\frac{Y_{m}}{Y_{m 0}}\right)^{m_{m}}\right]\right)
$$

where $D_{s a r}$ is the limit value of the damage variable related to the saturation of matrix cracking. $Y_{m(1)}$ is a scale parameter, and $m_{m}$ is a shape parameter. The identified values are

$$
D_{s a r}=1.0, \quad Y_{m 0}=0.60 \mathrm{MPa}, m_{m}=1.2
$$

Once the evolution law for matrix cracking is determined, that of the fiber damage variable can be identified. The values $D$, are very small, and the effect of fiber breakage will therefore be neglected for this material. Finally, the expression used to model the evolution laws of the inelastic strain are

$$
\alpha_{i}=\frac{<\sigma_{i}-\sigma_{t h}>+}{\sigma_{11}}
$$

where the index $i$ is equal to either 11 or $22,\langle\cdot\rangle$. denotes the positive part of the considered quantity, $\sigma_{i}$ is the applied stress in the $i$ direction, $\sigma_{t h}$ is a threshold stress and $\sigma_{0}$ is a scale parameter, and

$$
\alpha_{12}=\frac{<\tau_{c 4}-\tau_{1 h}>+}{\tau_{0}} \operatorname{Sgn}\left(\sigma_{12}\right)
$$

where $\sigma_{12}$ is the shear stress applied to the composite. $\tau_{\mathrm{th}}$ is another threshold value and $\tau_{0}$ is a scale parameter.

The introduction of the expression of $\tau_{\text {eq }}$ is due to the observation that, for many CMCs, the stress/strain curve obtained in a tension test at $45^{\circ}$ is close to the one measured in a losipescu shear test. This property has been observed for $\mathrm{SiC} / \mathrm{SiC}^{2}$ and $\mathrm{SiC} / \mathrm{CA} \mathrm{S}^{6}$ composites. A choice for $\tau_{e^{\prime},}$ which satisfies this property is given by

$$
\tau_{e^{\prime 4}}=\sqrt{\mid\left(\sigma_{12}\left[\sigma_{12}+\frac{3}{2}\left(\sigma_{11}+\sigma_{22}\right)\right] \mid\right.}
$$

Similarly, it is also possible to give an expression for $\tau_{\text {e } 4}$ by using tension and compression tests at $45^{\circ}$. The effect of the hydrostatic pressure is different in those two tests. The identified constants of eqns (27) and (28) defining the evolution laws of the inelastic strains are

$$
\begin{aligned}
& \sigma_{t h}=88 \mathrm{MPa}, \sigma_{0}=4.8 \mathrm{GPa} \\
& \tau_{l h}=77 \mathrm{MPa}, \tau_{0}=324 \mathrm{MPa}
\end{aligned}
$$

This model is implemented in the commercial finite-element code ABAQUS via a UMAT routine. ${ }^{7}$ Integrated laws are easy to implement, and reduce the computation cost. The results of the computations on a coupon specimen subjected to tension at $0^{\circ}$ or $45^{\circ}$ are compared with the experiments (Fig. I).

\section{APPLICATIONS}

The identified model is used to analyze two structures. The first computation is performed on a Iosipescu shear test to check the model and to show the limits of that type of shear test. Plates with holes made of 14 layers for a total thickness of $3 \mathrm{~mm}$ will also be studied.

In elasticity, it has been shown that the stress field in the ligament of a Iosipescu ${ }^{3}$ specimen is pure shear. The measurement and prediction of the mean shear stress have comparable values. However, the local stress in the center of the ligament is higher (Fig, 2).

Analyses of a plate with a hole loaded in the direction of the fibers for a temperature $T=1000^{\circ} \mathrm{C}$ (Fig. 3) show a good agreement between the simulations and the different strain measurements on the plate

\section{THERMO-MECHANICAL AND CYCLIC LOADINGS}

In most CMCs, the matrix and the fiber are not subject to fatigue, but the properties of the interface between the matrix and the fiber change. ${ }^{8}$ The identified degradation mechanism of fatigue is modeled by a wear law of the interface. The extension of a similar law used in monotonic load has been performed by including the interface wear law. ${ }^{9}$ The wear law can be identified from only one fatigue experiment. The micro-mechanical analyses are then used to extend the model to more complex cyclic load histories. ${ }^{10}$

The increase of temperature gives rise to creep in the fibers, and also to oxidation of some constituents of the composite. Under thermo-mechanical loads, only creep

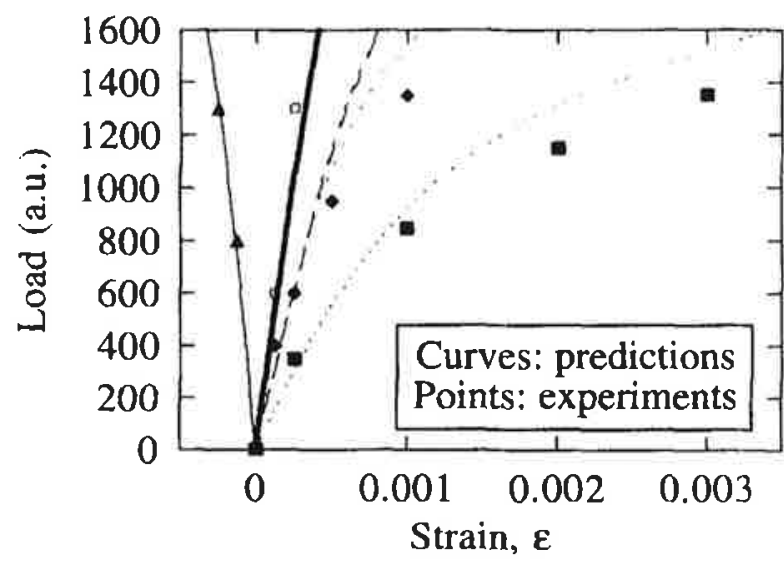

Fig. 3. Tension curves of a plate with a hole $\left(T=1000^{\circ} \mathrm{C}\right)$. 


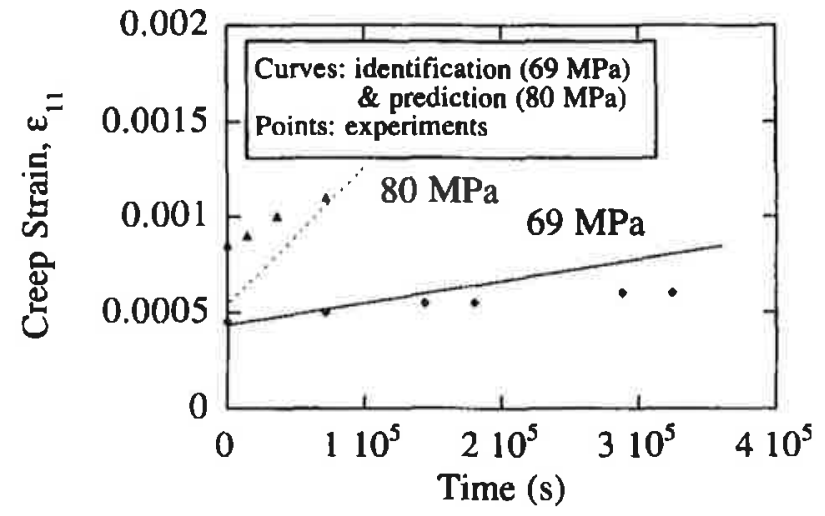

Fig. 4. Creep curves of a $[0,90] \mathrm{SiC} / \mathrm{SiC}$ composite at $0^{\circ}$ $\left(T=1200^{\circ} \mathrm{C}\right)$.

of the fiber will be analyzed and modeled by Norton's law:-The creep law of the composite is a result of the analysis of the same elementary cell used to study monotonic loads. When the fibers are creeping, the stress redistribution between the fiber and the matrix may create new matrix cracks. The identification of the creep law is obtained from creep test on the composite (Fig. 4) when the temperature $T=1200^{\circ} \mathrm{C}$.

Lastly, the extension to creep-cyclic thermomechanical loadings is a combination of the two previous cases with some couplings which are still under analysis.

\section{ACKNOWLEDGEMENTS}

This work was supported by the Advanced Research Project Agency through the University Research Initiative under Office of Naval Research Contract No. N-0001492-J-1808.

\section{REFERENCES}

1. Burr, A., Hild, F, and Leckie, F. A., Micro-mechanics and continuum damage mechanics. Arch. Appl. Mech., $1995,65,437-456$.

2. Pluvinage, $P$., Etude expérimentale et simulation numérique du comportement mécanique de matériaux composites $\mathrm{SiC} / \mathrm{SiC}$. Influence des paramètres de stratification et d'élaboration. Ph.D. thesis; Université Bordeaux I, 1991.

3. Iosipescu, N., New accurate procedure for single shear testing of metals. J. Mater., 1967, 2, 537-566.

4. Burr, A., Micromécanique et comportement de matériaux hétérogènes. Ph.D. thesis, Université Paris VI, 1995.

5. Weibull, W., A statistical theory of the strength of materials. Royal Swedish Institute in Engineering Research, Report No. 151.

6. Cady, C., Makin, T. J. and Evans, A. G., Silicon carbide calcium aluminosilicate - a notch-insensitive ceramicmatrix composite. J. Am. Ceram. Soc., 1995, 78, 77-82.

7. Hibbitt, H. D., Karlsson, B. I. and Sorensen, P., ABAQUS, (version 5.5), 1995.

8. Rouby, D. and Reynaud, P., Fatigue behaviour related to interface modification during load cycling in ceramicmatrix fibre composites. Compos. Sci. Technol., 1993, 48, 109-118.

9. Burr, A. and Hild, F., Ultimate tensile strength during fatigue of fiber-reinforced ceramic-matrix composites. Mech. Res. Commun., 1995, 22, 401-406.

10. Burr, A., Hild, F. and Leckie, F. A., On the mechanical behaviour under cyclic loading of ceramic-matrix composites. Mater. Sci. Eng., (in press). 